\title{
Electrolyte Leakage and Evolution of Ethylene and Ethane from Pepper Leaf Disks Following Temperature Stress and Fatty Acid Infiltration
}

\author{
Geeta K. Nanaiah ${ }^{1}$ and Jeffrey A. Anderson ${ }^{2}$ \\ Department of Horticulture and Landscape Architecture, Oklahoma State University, Stillwater, \\ OK 74078-0511
}

Additional index words. Capsicum annuum, stearic acid, oleic acid, linoleic acid, linolenic acid, eicosatrienoic acid, eicosapentaenoic acid, freezing, heating, membrane, peroxidation

\begin{abstract}
Electrolyte leakage (EL) and ethane : ethylene ratio (EER) responses of pepper (Capsicum annuum L. 'Early Calwonder') leaf disks to temperature stresses were in close agreement. Midpoints of sigmoidal response curves following freezing stress were $-\mathbf{4 . 6}$ and $-4.4 C$ for $E L$ and EER, respectively, and 49.0 and $48.7 \mathrm{C}$ following hightemperature stress. Leaf disks exposed to temperatures below $-4 \mathrm{C}$ in freezing experiments were induced to freeze while disks held at $\mathbf{- 4 C}$ and higher avoided freezing by supercooling. Evolution of ethane and EL were measured from disks infiltrated with a saturation series of 18-C fatty acids ranging from 0 to 3 double bonds. Only cis-9,12,15 linolenic acid (18:3 n-3) stimulated ethane production and EL. In a second fatty acid experiment with 18 and $20-C$ acids with a double bond $3(n-3)$ or $6(n-6)$ carbons from the nonpolar end of the molecule, n-3 fatty acids stimulated more ethane than n-6 acids with the same number of carbons. Trienoic 18-C fatty acids stimulated more ethane than trienoic 20-C acids. Both 18-C trienoic acids yielded significantly greater EL, while values from 20-C fatty acids were only slightly higher than those of controls. Propyl gallate, a free radical scavenger, reduced ethane production without decreasing EL or $\mathrm{K}^{+}$leakage.
\end{abstract}

Responses of plant cells to acute temperature stress involve membrane dysfunctions. Although many viability tests are based on selective permeability properties of the plasma membrane, little is known regarding the events taking place at the membrane level during and after tissue exposure to stress. In some cases it is not clear which events contribute to loss of viability and which are a consequence.

One focus of stress research has been on membrane lipids. Treatment of organelles with ozone (Pauls and Thompson, 1980) and sulfite (Peiser et al., 1982) resulted in peroxidation of unsaturated fatty acids in a free-radical-mediated reaction. Breakdown products of fatty acid hydroperoxides include aldehydes (Benedetti et al., 1980; Esterbauer et al., 1982) and low molecular weight hydrocarbons such as ethane (Dumelin and Tappel, 1977). Lieberman and Mapson (1962) demonstrated the requirement for unsaturated fatty acids for ethane production using a model system. Freezing (Elstner and Konze, 1976; Harber and Fuchigami, 1986), pollution (Bressan et al., 1979), water deficit (Kobayashi et al., 1981), and chilling at high light intensity (Wise. and Naylor, 1987) have stimulated plant tissues to evolve ethylene and ethane. Increased ethylene production was associated with slight or moderate injury, and ethane was evolved from severely injured or killed cells. Several researchers have proposed using the ratio of ethane to ethylene as an index of injury (Bressan et al., 1979; Elstner and Konze, 1976; Harber and Fuchigami, 1986). Our objectives were to determine the relationship between EER and EL from pepper leaf disks following heat and freezing stress and the effects of the bond

Received for publication 26 Nov. 1991. Accepted for publication 13 Apr. 1992. Journal article no. 6121 of the Agr. Expt. Sta., Oklahoma State Univ., Stillwater. Research supported in part-by U.S. Dept. of Agriculture Special Grant no. 88-34146-3401. We gratefully acknowledge Niels Maness and Michael Smith for use of equipment. The cost of publishing this paper was defrayed in part by the payment of page charges. Under postal regulations, this paper therefore must be hereby marked advertisement solely to indicate this fact.

'Graduate Assistant.

${ }^{2}$ Associate Professor. To whom reprint requests should be addressed. structure of exogenously applied fatty acids on EL and evolution of ethane.

\section{Materials and Methods}

Plant material. 'Early Calwonder' pepper seeds were planted in 36-liter pots filled with commercial potting mix (Fafard GP Mix, Springfield, Mass.). Plants were grown in a growth chamber maintained at $23 / 20 \mathrm{C}$ (day/night) cycles with a daylength of $14 \mathrm{~h}$ and light intensity of $\approx 500 \mu \mathrm{mol} \cdot \mathrm{m}^{-2} \mathrm{~s}^{-1}$ at canopy height provided by fluorescent and incandescent bulbs. Relative humidity ranged from $\approx 45 \%$ to $65 \%$. Plants were fertilized at each watering with $0.75 \mathrm{~g} 20 \mathrm{~N}-8.7 \mathrm{P}-16.6 \mathrm{~K}$ soluble fertilizer per liter (Peters Professional, W.R. Grace \& Co., Fogelsville, Pa.). Leaf disks (14-mm diameter) were excised with a cork borer from fully expanded leaves from 60- to 80-day-old plants. Disks were rinsed with three changes of distilled water to remove exogenous electrolytes.

Temperature stress. Thirteen leaf disks were placed into each $25 \times 150$-mm test tube containing 2 -ml distilled water to prevent secondary water stress. Disks were floating, partially submerged in liquid, or contacting water through adhesive forces. Samples were exposed to high or low temperatures by placing tubes into circulating baths for $30 \mathrm{~min}$ at the prescribed treatment temperature. Temperatures were monitored by threading a copper/constantan thermocouple wire (0.1-mm diameter) through a disk in an extra test tube at each treatment temperature. The thermocouple wire was inserted in a serpentine manner with the junction in contact with the tissue. Disks exposed to temperatures below $-4 \mathrm{C}$ in freezing stress studies were nucleated with ice chips to initiate freezing when the tissue temperature dropped below 0C. The addition of ice to the tube caused the $2 \mathrm{ml}$ of water in the bottom of the tube to freeze. All disks exposed to temperatures below $-4 \mathrm{C}$ had frozen, based on water-soaking, while samples exposed to $-4 \mathrm{C}$ and higher supercooled. Fol-

Abbreviations: EER, ethane: ethylene ratio; EL, electrolyte leakage. 
lowing temperature treatment, three disks were transferred to a test tube containing 20-ml distilled water for EL determinations and the remaining 10 were blotted and placed into $14.5-\mathrm{ml}$ serum bottles with septa for EER measurements. EL and EER responses were measured after $24-\mathrm{h}$ incubation at $24 \mathrm{C}$ in the dark.

Fatty acids. Fatty acid emulsions were prepared from free acids (Sigma Chemical Co., St. Louis.). Leaf disks were vacuum infiltrated in treatment solutions for $5 \mathrm{~min}$ before slow equilibration to atmospheric pressure. Samples were kept at $24 \mathrm{C}$ for $4 \mathrm{~h}$ after vacuum infiltration. For each experimental unit, three disks were transferred to a tube with $20-\mathrm{ml}$ distilled water for EL measurement and 10 disks were blotted and placed in a serum bottle for ethane measurement. A preliminary study was carried out to determine whether ethanol, the primary solvent for the fatty acids, was affecting tissue responses since it is a free radical scavenger (Dhindsa et al., 1982). In this study, cis9, 12, 15 linolenic acid (5mM) was dissolved in ethanol, ranging in final concentration from $0.3 \%$ to $3.0 \%(\mathrm{v} / \mathrm{v})$. Control disks were infiltrated in ethanol from $0 \%$ to $3 \%$ without linolenic acid. Ethanol from $0.3 \%$ to $3.0 \%$ did not significantly affect EL or production of ethane (data not presented).

The first of three fatty acid infiltration experiments employed a saturation series of $18-\mathrm{C}$ fatty acids containing from zero to three double bonds. Stearic, cis-9 oleic, cis-9, 12 linoleic, and cis-9, 12, 15 linolenic acids were dissolved in ethanol $[0.9 \%(\mathrm{v} /$ v) final concentration] then diluted to $5 \mathrm{~mm}$ in $0.01 \%(\mathrm{v} / \mathrm{v})$ Tween 60 (polyoxyethylenesorbitan). Stearic acid required warming to dissolve. Leaf disks were vacuum-infiltrated in fatty acids or in control solutions, both with and without Tween 60 . Filter paper soaked in a mass of fatty acid solution equal to the mass increase of infiltrated disks produced negligible or undetectable levels of ethane, indicating that little or no autoxidation occurred.

The second experiment examined the effect of bond location in 18- and 20-C acids with a double bond $3(\mathrm{n}-3)$ or 6 carbons (n-6) from the nonpolar end of the molecule. Cis-9, 12, 15 linolenic (18:3 n-3); cis-6, 9, 12 linolenic (18:3 n-6); cis-11, 14, 17 eicosatrienoic (20:3 n-3); cis-8, 11, 14 eicosatrienoic (20:3 n-6); and cis-5, 8, 11, 14, 17 eicosapentaenoic (20:5 n-3) acids were dissolved in ethanol (final concentration of $0.3 \%$ ), then diluted to $5 \mathrm{~mm}$ in distilled water. All fatty acids in this experiment had three double bonds except for eicosapentaenoic with five. The third experiment examined the effects of 0.1 and $1.0 \mathrm{~mm}$ propyl gallate on ethane production, EL, and $\mathrm{K}^{+}$leakage from disks co-infiltrated with $5 \mathrm{~mm}$ cis-9, 12, 15 linolenic acid.

$E L, K^{+}$leakage, and hydrocarbon determinations. EL was measured using a conductance meter (Model 35, Yellow Springs Instrument Co., Yellow Springs, Ohio) after incubation on an orbital shaker at 24C (initial readings), then after autoclaving and cooling to $24 \mathrm{C}$ (final readings). Disks from temperaturestress experiments were incubated $24 \mathrm{~h}$ before initial and final readings, while disks infiltrated in fatty acid experiments were incubated $4 \mathrm{~h}$. Preliminary time-course studies indicated that electrolytes leached from infiltrated tissues more rapidly than from noninfiltrated tissues before initial readings. Electrolytes leached rapidly from infiltrated and noninfiltrated tissues following autoclaving. Data were expressed as initial readings/final readings. Potassium leakage was measured from a 1:1 dilution of the EL solution with an atomic absorption spectrophotometer (Model 2380, Perkin Elmer, Norwalk, Conn.). Concentrations were calculated from standard curves obtained at $766.5 \mathrm{~nm}$. Ethylene and ethane measurements were conducted using gas chromatography. One milliliter headspace gas was removed by syringe from a $14.5-\mathrm{ml}$ serum bottle containing 10 disks and injected into a Tracer 540 gas chromatograph (Tracor Instruments, Austin, Texas) equipped with a flame ionization detector. The 1.8-m column was packed with activated alumina. Gas concentrations were calculated from response factors determined from standards (Scott Specialty Gases, Plumsteadville, $\mathrm{Pa})$.

Ethane and ethylene values were transformed $\left[\left(\mathrm{nl} \cdot \mathrm{g}^{-1} \cdot \mathrm{h}^{-1}+\right.\right.$ $0.1)^{-2}$ ] before EER calculations to accommodate 0 values (nondetectable amounts). Mean separation for EL and ethane data from fatty acid experiments was carried out using Duncan's multiple range test at $P=0.05$ following analyses of variance. Midpoints of sigmoidal response curves in temperature stress studies were estimated using the nonlinear equation described by Ingram (1985), except that absolute values of temperatures were used and midpoints multiplied by -1 in freezing data. All treatment levels contained three samples on each date and each experiment was conducted three times.

\section{Results and Discussion}

Temperature stress. Ethylene production from low temperature-stressed leaf disks increased from $0.7 \mathrm{nl} \cdot \mathrm{g}^{-1} \cdot \mathrm{h}^{-1}$ at $0 \mathrm{C}$ to a maximum of $2.2 \mathrm{nl} \cdot \mathrm{g}^{-1} \cdot \mathrm{h}^{-1}$ at $-4 \mathrm{C}$ (Fig. 1A). Ethylene was not detected below $-4 \mathrm{C}$. In contrast, ethane was not detected above $-4 \mathrm{C}$. Ethane production increased to $0.8 \mathrm{nl} \cdot \mathrm{g}^{-1} \cdot \mathrm{h}^{-1}$ at $-5 \mathrm{C}$ then decreased to $0.5 \mathrm{nl} \cdot \mathrm{g}^{-1} \cdot \mathrm{h}^{-1}$ for leaves at $-8 \mathrm{C}$.

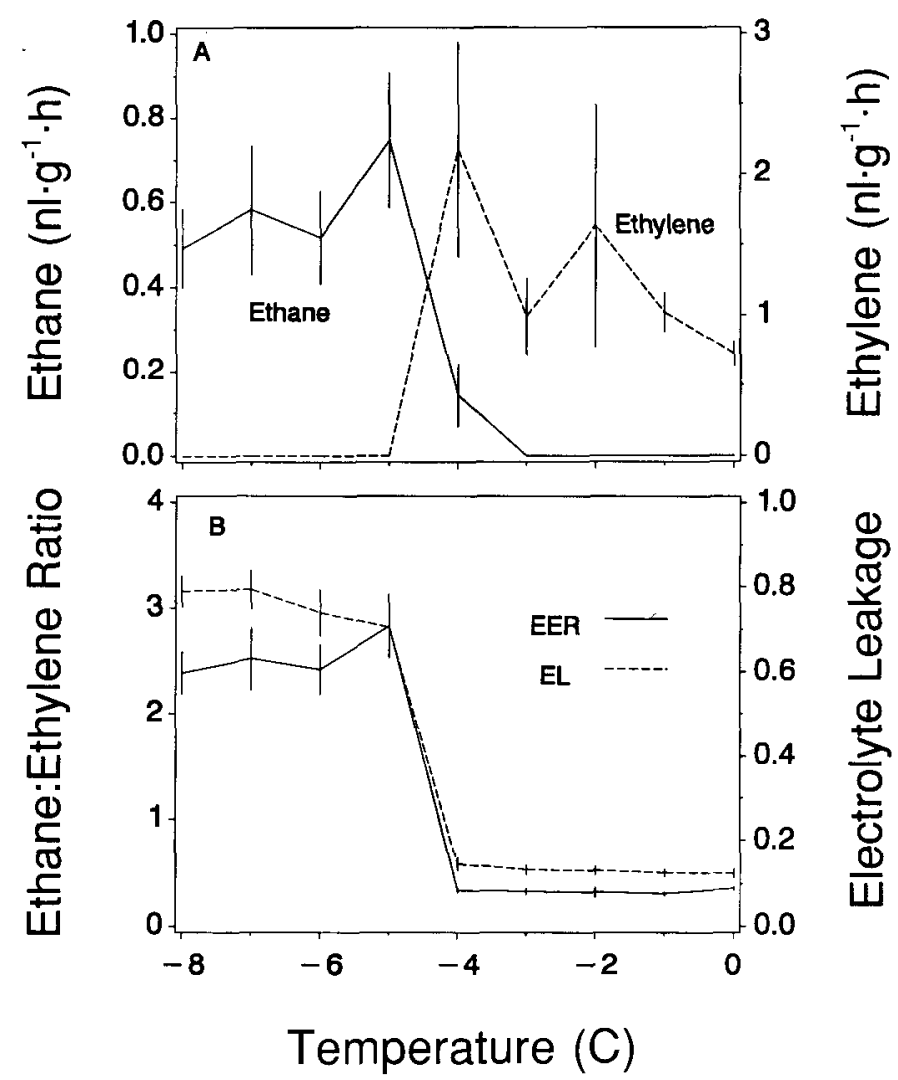

Fig. 1. (A) Production of ethylene and ethane. (B) EER and EL from pepper leaf disks following low temperature exposure. Ethylene and ethane values were transformed $\left[\left(\mathrm{nl} \cdot \mathrm{g}^{-1} \cdot \mathrm{h}^{-1}+0.1\right)^{-2}\right]$ to accommodate zero values (nondetectable amounts) before calculation of EER. Disks exposed to temperatures from 0 to $-4 \mathrm{C}$ supercooled, while samples kept for 30 min below $-4 \mathrm{C}$ were induced to freeze by adding ice chips to the tubes. Values are means \pm SE of nine measurements (three subsamples on each of three dates). 
The EER and EL exhibited sharp transitions from -4 to $-5 \mathrm{C}$ following low temperature exposure (Fig. 1B). Midpoints of sigmoidal response curves for EL and EER were - $4.6 \pm 0.1$ and $-4.4 \pm 0.2$, respectively. Although the relationship between EER and EL was very close, correlation coefficients may not be appropriate due to the uneven distribution of values arising from the abrupt transition from uninjured to killed tissues.

Disks kept at temperatures from 0 to $-4 \mathrm{C}$ supercooled and showed no signs of damage. Tissues exposed to below - 4C were induced to freeze and were killed based on EL and EER. The increased EER in frozen disks reflected elevated ethane production, presumably from fatty acid decomposition, and decreased ethylene production from damage to the membraneassociated ethylene-forming system.

Heat-stressed tissues exhibited responses similar to those subjected to low temperatures. Ethylene production from heat-stressed leaf disks increased as exposure temperatures increased from 21 to $43 \mathrm{C}$ (Fig. 2A). After reaching a maximum of $8.7 \mathrm{nl} \cdot \mathrm{g}^{-1} \cdot \mathrm{h}^{-1}$ at $43 \mathrm{C}$, ethylene evolution decreased to $0.3 \mathrm{nl} \cdot \mathrm{g}^{-1} \cdot \mathrm{h}^{-1}$ at $48 \mathrm{C}$, above which no ethylene was detected. Ethane was not detected below 49C. Ethane levels increased to a maximum of 0.3 $\mathrm{nl} \cdot \mathrm{g}^{-1} \cdot \mathrm{h}^{-1}$ at $51 \mathrm{C}$ and declined at the higher temperatures. The EER and EL exhibited sharp transitions between 48 and 50C in heat-stressed disks (Fig. 2B). Midpoints of sigmoidal response curves for EL and EER were $49.0 \pm 0.1$ and $48.7 \pm 0.1$, respectively. The EER decreased between 21 and $43 \mathrm{C}$, then increased to a maximum at $51 \mathrm{C}$ and decreased from 51 to $55 \mathrm{C}$.

Ethylene was a more sensitive indicator of moderate heat stress than EL. Ethylene production was reported to be a more

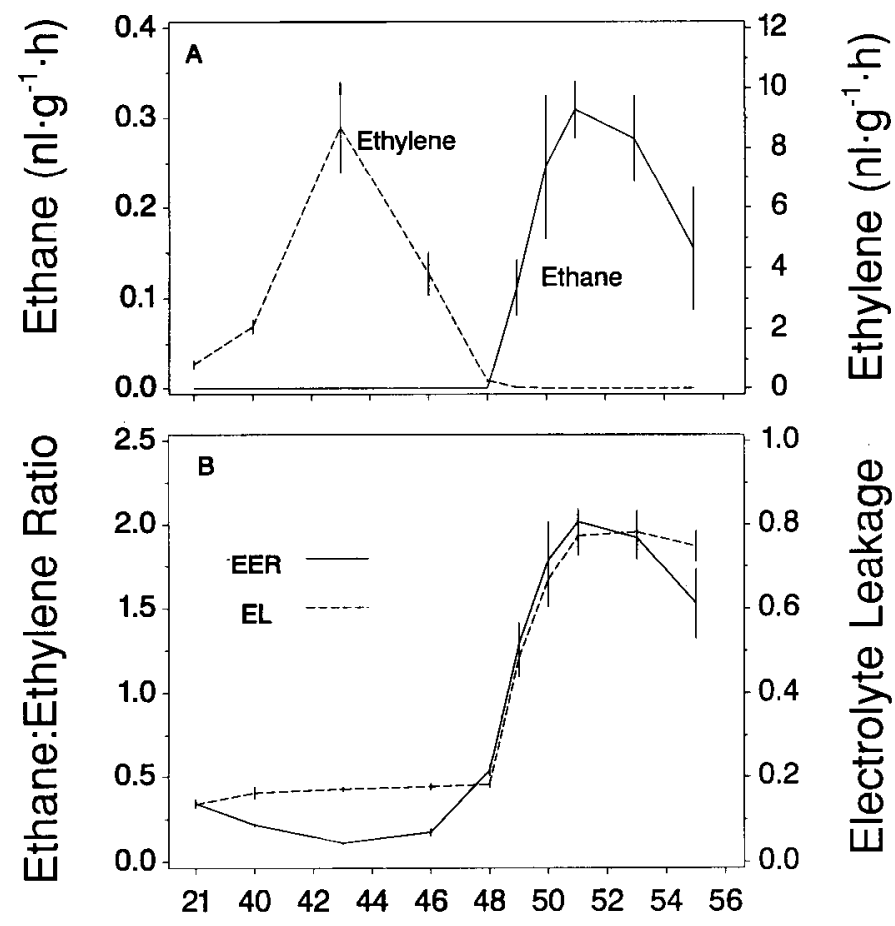

\section{Temperature $(\mathrm{C})$}

Fig. 2. (A) Production of ethylene and ethane. (B) EER and EL from pepper leaf disks following high temperature exposure. Ethylene and ethane values were transformed $\left[\left(\mathrm{nl} \cdot \mathrm{g}^{-1} \cdot \mathrm{h}^{-1}+0.1\right)^{-2}\right]$ to accommodate zero values (nondetectable amounts) before calculation of EER. Disks were kept at each temperature for $30 \mathrm{~min}$. Values are means \pm SE of nine measurements (three subsamples on each of three dates). sensitive symptom of membrane injury than EL in maple (Acerrubrum L.) leaves following sulfur dioxide fumigation (Roberts et al., 1990). The cause of the decline in ethane production after reaching a maximum is unknown, but similar results were reported for water-stressed leaf tissue (Kobayashi et al., 1981). Based on their results and the report by Curtis (1969) that autoclave apical buds produced negligible amounts of ethane, Kobayashi et al. (1981) suggested that inactivation of enzymes involved in ethane synthesis could be responsible for decreased ethane production in the most-severely stressed tissues. The reduction in ethane production from 51 to $55 \mathrm{C}$ in the heat stress experiments may be related to thermal instability of the enzyme(s) involved in ethane formation. Lipoxygenase (EC 1.13.11.12) has been identified as the enzyme catalyzing the oxidation of polyunsaturated fatty acids to hydroperoxides (Siedow, 1991). Lipoxygenase activity in pea (Pisium sativum L.) flour was stable for $30 \mathrm{~min}$ at $50 \mathrm{C}$, but lost $70 \%$ of activity after heating to $60 \mathrm{C}$ for $15 \mathrm{~min}$ (Henderson et al., 1991). Although hydroperoxide cleavage by enzymes such as hydroperoxide lyase represents another step that is potentially heat sensitive, a nonenzymic pathway for peroxidation of membrane lipids in tissue homogenates has also been described (Mead, 1976). Using EER as an index of injury appears to be appropriate for heat and freezing stress of mature pepper leaves. However, different types of stresses (Kimmerer and Kozlowski, 1982) or different growth phases (Shirazi et al., 1990) may elicit dissimilar patterns of stress responses.

Fatty acids. The first experiment involved a saturation series of 18-C fatty acids. Only the trienoic compound, linolenic acid (18:3), increased ethane production relative to controls (Fig. 3A). Similarly, linolenic acid was the only 18-C fatty acid in this experiment to stimulate EL (Fig. 3B). Konze and Elstner (1978) reported that ethane evolution from potato (Solanum tuberosum L.) mitochondria was increased by $10 \mathrm{~mm}$ linolenic acid and concluded that ethane was formed from linolenic acid. John and Curtis (1977) came to the same conclusion after finding that linolenic acid stimulated ethane production and linoleic, oleic, stearic, and palmitic acids did not affect ethane production from an acetone extract from bean (Phaseolus vulgaris) seedlings.

Lipoxygenase catalyzes the oxidation of polyunsaturated fatty acids to hydroperoxides (Siedow, 1991). Although linoleic acid cent sins a 1,4-pentadiene structure and is therefore a substrate for oxidation by lipoxygenase (Galliard, 1978), it did not induce ethane evolution following tissue infiltration. Linoleic acid may have been oxidized to metabolizes other than ethane. In a model system, pentane was the major hydrocarbon gas produced from the iron, copper, and hematin catalyzed peroxidation of linoleic acid (Dumelin and Tappel, 1977). Thermolysis of autoxidized linolenic and linoleic acids produced ethane and pentane, respectively, as the major products (Evans et al., 1968). If linoleic acid was oxidized in our experiments, it apparently did not yield toxic byproducts or catalyze oxidation of membrane fatty acids sufficiently to increase membrane permeability to electrolytes. Linolenic acid may have been singularly effective in activating pepper phospholipase(s) (EC 3.1.4.4) that release fatty acids from membrane lipids. However, Galliard (1978) found that linoleic acid was autocatalytic in activating phospholipase in cauliflower mitochondria.

In the second experiment with fatty acids, the n-3 acids elicited more ethane than n-6 acids with a corresponding number of carbons, and 18-C compounds produced more ethane than 20-C fatty acids (Fig. 4). Electrolyte leakage values were significantly higher in all fatty acid treatments than in the controls. 

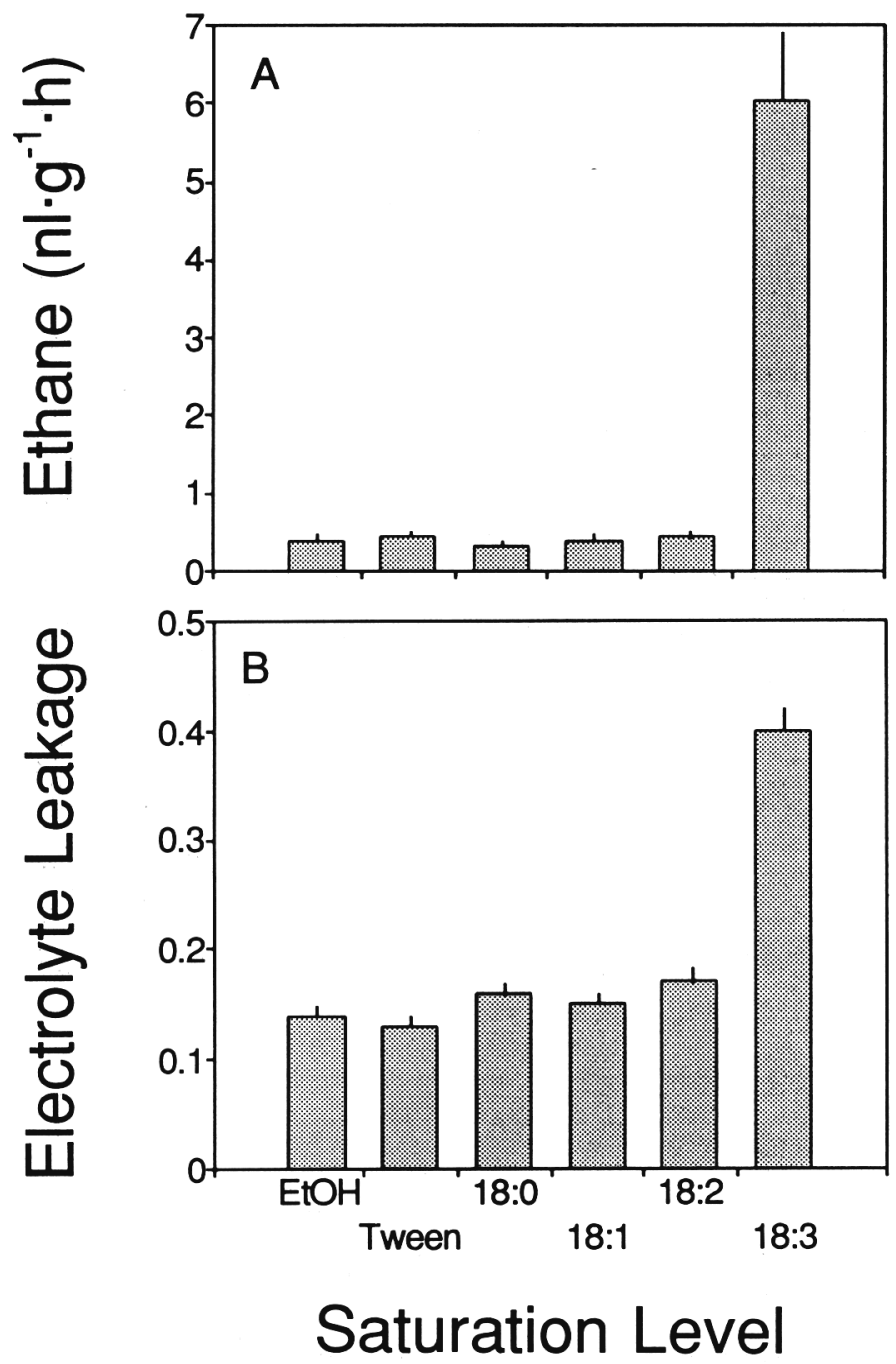

(A) Evolution of ethane. (B) EL from pepper leaf disks infiltrated with a $5 \mathrm{~mm}$ aqueous solution of $18-\mathrm{C}$ fatty acids containing from 0 to 3 double bonds, ethanol, and Tween, or with distilled water plus ethanol (EtOH), or distilled water plus Tween 60 (Tween). Ethanol was used as the primary solvent for fatty acids [final concentration of $0.9 \%(\mathrm{v} / \mathrm{v})]$ and dilution was made with an aqueous solution of Tween 60 [final concentration of $0.01 \%(\mathrm{v} / \mathrm{v})$ ]. Values are means \pm SE of nine measurements (three subsamples on each of three dates).

However, 18-C acids triggered more EL than 20-C acids. Although 18:3 n-6 and 18:2 n-6 fatty acids were not compared in the same series of experiments, results presented in Figs. 3 and 4 suggest that 18:3 n-6 was more effective than 18:2 n-6 in stimulating EL and ethane production. Schobert and Elstner (1980) reported that cell suspensions of Phaeodactylum triconutum (Bohlin) produced large amounts of ethane after addition of n3 fatty acids, but n-6 and n-9 acids resulted in either a slight stimulation or depression. Our results are in general agreement, however, we observed greater specificity based on number of double bonds and number of $\mathrm{C}$ atoms. Eicosapentaenoic acid $(20: 5 n-3)$ caused the highest production of ethane $(14.7 \pm 2.0$ $\left.\mathrm{nl} \cdot \mathrm{g}^{-1} \cdot \mathrm{h}^{-1}\right)$ and loss of electrolytes $(0.52 \pm 0.05)$ of the fatty acids we have examined. Either eicosapentaenoic acid was a precursor of ethane or it triggered oxidation of linolenic acid from the membrane. The observed specificity in EL and ethane
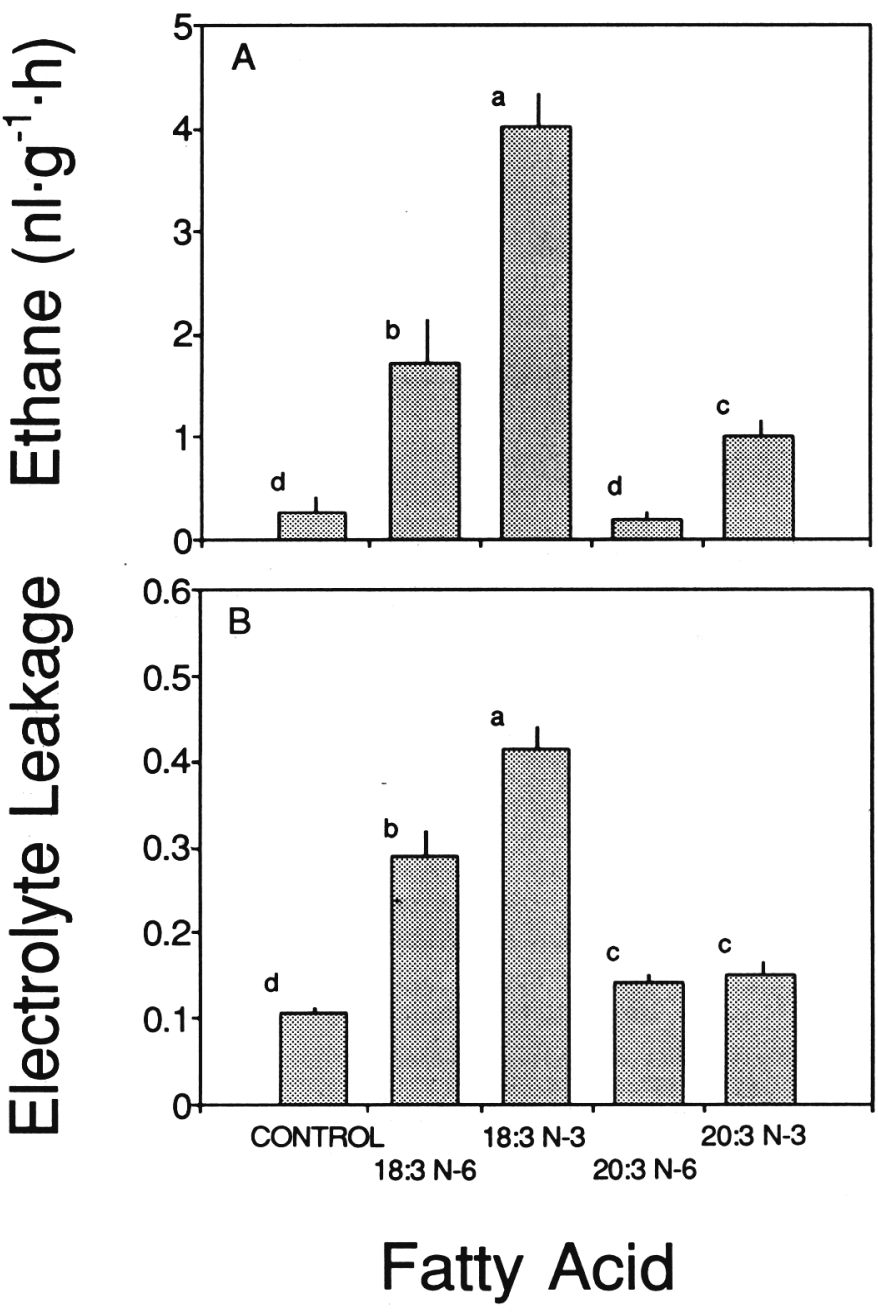

Fig. 4. (A) Evolution of ethane. (B) EL from pepper leaf disks infiltrated with a $5 \mathrm{~mm}$ aqueous solution of 18 - and 20-C fatty acids containing a double bond $3(n-3)$ or 6 (n-6) carbons from the nonpolar end of the molecule, ethanol and Tween, or with distilled water, ethanol $[0.3 \%(\mathrm{v} / \mathrm{v})]$, and Tween $60[0.01 \%(\mathrm{v} / \mathrm{v})]$ as the control. Values are means \pm SE of nine measurements (three subsamples on each of three dates). Mean separation at $P=0.05$ with Duncan's multiple range test.

production based on fatty acid bond structure may suggest enzymatic involvement in oxidation.

Propyl gallate was effective in reducing ethane production, but not loss of membrane selective permeability based on EL and loss of $\mathrm{K}^{+}$(Table 1). Concentrations of propyl gallate higher than $1 \mathrm{~mm}$ did not decrease EL (data not presented). Propyl gallate may not have prevented lipid peroxidation, but acted on a subsequent step in the reaction series leading to ethane. Riley et al. (1974) measured ethane and peroxidation based on thiobarbituric acid-reacting substances from rat liver homogenates. They found that alpha-tocopherol blocked peroxidation and ethane production in liver homogenates.

Antioxidants and enzymes such as superoxide dismutase (EC 1.15.1.1), catalase (EC 1.11.1.6), and peroxidase (EC 1.11.1.7) play a role in cellular maintenance by detoxifying free radicals formed by enzymic and nonenzymic processes (Konze and Elstner, 1978). Yeast (Saccharomyces cerevisiae Meyer) cells, which normally contain very little if any polyenoic fatty acids, had increased mortality when enriched in linolenic vs. oleic acid 
Table 1. Effect of propyl gallate and linolenic acid on ethane evolution and loss of $\mathrm{K}+$ and electrolytes from pepper leaf disks. Values are means \pm SE of nine measurements (three subsamples on each of three dates).

\begin{tabular}{ccccc}
\hline \hline $\begin{array}{c}\text { Linolenic acid } \\
(\mathrm{mM})\end{array}$ & $\begin{array}{c}\text { Propyl gallate } \\
(\mathrm{mM})\end{array}$ & $\begin{array}{c}\text { Ethane } \\
\left(\mathrm{nl} \cdot \mathrm{g}^{-1} \cdot \mathrm{h}^{-1}\right)\end{array}$ & $\begin{array}{c}\text { Electrolyte } \\
\text { leakage }\end{array}$ & $\begin{array}{c}\mathrm{K}^{+} \\
\left(\mu \mathrm{g} \cdot \mathrm{g}^{-1}\right)\end{array}$ \\
\hline 0 & 0 & $0.3 \pm 0.1$ & $0.12 \pm 0.01$ & $0.2 \pm 0.5$ \\
0 & 0.1 & $0.4 \pm 0.1$ & $0.11 \pm 0.01$ & $0.2 \pm 0.3$ \\
0 & 1.0 & $0.1 \pm 0.1$ & $0.13 \pm 0.01$ & $1.2 \pm 0.5$ \\
5 & 0 & $5.4 \pm 1.2$ & $0.30 \pm 0.01$ & $7.1 \pm 0.7$ \\
5 & 0.1 & $2.1 \pm 0.3$ & $0.31 \pm 0.03$ & $5.0 \pm 1.0$ \\
5 & 1.0 & $1.0 \pm 0.1$ & $0.37 \pm 0.02$ & $6.4 \pm 0.6$ \\
LA*PG $^{z}$ & & $*$ & & NS \\
Linear & & $*$ & NS & NS \\
Quadratic & & $*$ & & \\
\hline
\end{tabular}

${ }^{\mathrm{L}} \mathrm{LA}=$ linolenic acid, $\mathrm{PG}=$ propyl gallate.

${ }^{\text {Ns }}$ *Nonsignificant or significant at $P=0.05$.

from the culture medium (Bilinski et al., 1989). Further, mutants deficient in superoxide dismutase exhibited a higher mortality than the wild type, suggesting the role of free radicals. Although propyl gallate did not reduce EL in our study, stresses or tissue aging may overcome the cells free radical scavenging ability and cause damage to biomolecules and membranes.

We can not be sure of the mechanism or location of reactions taking place after tissue infiltration. Although they could be taking place in the free spaces of the cell wall and in the intercellular spaces, the observed increases in EL and $\mathrm{K}^{+}$leakage indicate that fatty acids or their byproducts came in contact with the plasma membrane. Cellular involvement in fatty acid breakdown was supported by preliminary experiments indicating that fatty acids did not undergo significant breakdown when absorbed onto filter paper. Infiltration with unsaturated fatty acids may have simulated a stress-triggered, phospholipase-controlled release of fatty acids from membrane lipids. Tissues undergoing low temperature stress have exhibited an increase in phospholipase D (EC 3.1.4.4) activity (Yoshida, 1979) and free fatty acids (Kendall et al., 1985). Even if the fatty acid breakdown in our system was unrelated to events occurring during stressinduced membrane degradation, the molecular specificity in eliciting membrane leakage is notable.

\section{Literature Cited}

Benedetti, A., M. Comporti, and H. Esterbauer. 1980. Identification of 4-hydroxynonenal as a cytotoxic product originating from the peroxidation of liver microsomal lipids. Biochim. Biophys. Acta 620:281-296.

Bilinski, T., J. Litwidska, M. Blaszcynski, and A. Bajus. 1989. Superoxide dismutase deficiency and the toxicity of the products of autooxidation of polyunsaturated fatty acids in yeast. Biochim. Biophys. Acta 1001:102-106.

Bressan, R.A., L. LeCureux, L.G. Wilson, and P. Filner. 1979. Emission of ethylene and ethane by leaf tissue exposed to injurious concentrations of sulfur dioxide or bisulfite ion. Plant Physiol. 63:924930.

Curtis, R.W. 1969. Oxygen requirement for ethane production in vitro by Phaseolus vulgaris. Plant Physiol. 44:1368-1370.

Dhindsa, R.S., P. Plumb-Dhindsa, and D.M. Reid. 1982. Leaf senescence and lipid peroxidation: Effects of some phytohormones, and scavengers of free radicals and singlet oxygen. Physiol. Plant. 56:453457.

Dumelin, E.E. and A.L. Tappel. 1977. Hydrocarbon gases produced during in vitro peroxidation of polyunsaturated fatty acids and decomposition of preformed hydroperoxides. Lipids 12:894-900.
Eistner, E.F. and J.R. Konze. 1976. Effect of point freezing on ethylene and ethane production by sugar beet leaf disks. Nature 263:351352.

Esterbauer, H., K.H. Cheeseman, M.U. Dianzi, G. Poli, and T.F. Slater. 1982. Separation and characterization of the aldehydic products of lipid peroxidation stimulated by $\mathrm{ADP}-\mathrm{Fe}^{2+}$ in rat liver microsomes. Biochem. J. 208:129-140.

Evans, C.D., G.R. List, A. Dolev, D.G. McConnell, and R.L. Hoffmann. 1968. Pentane from thermal decomposition of lipoxidasederived products. Lipids 2:432-434.

Galliard, T. 1978. Lipolytik and lipoxygenase enzymes in plants and their action in wounded tissues, p. 155-201. In: Biochemistry of wounded plants. Walter de Gruyter \& Co., Berlin.

Harber, R.M. and L.H. Fuchigami. 1986. The relationship of ethylene and ethane production to tissue damage in frozen rhododendron leaf disks. J. Amer. Soc. Hort. Sci. 111:434-436.

Henderson, H.M., G. Plank, and H. Sustackova. 1991. Thermal inactivation of pea flour lipoxygenase. J. Food Biochem. 15:107-115.

Ingram, D. 1985. Modeling high temperature and exposure time interactions on Pittosporum tobira root cell membrane thermostability. J. Amer. Soc. Hort. Sci. 110:470-473.

John, W.W. and R.W. Curtis. 1977. Isolation and identification of the precursor of ethane in Phaseolus vulgaris L. Plant Physiol. 59:521522 .

Kendall, E.J., B.D. McKersie, and R.H. Stinson. 1985. Phase properties of membranes after freezing injury in winter wheat. Can. J. Bot. 63:2274-2277.

Kimmerer, T.W. and T.T. Kozlowski. 1982. Ethylene, ethane, acetaldehyde, and ethanol production by plants under stress. Plant Physiol. 69:840-847.

Kobayashi, K., L.H. Fuchigami, and K.E. Brainerd. 1981. Ethylene and ethane production and electrolyte leakage of water-stressed 'Pixy plum leaves. HortScience 16:57-59.

Konze, J.R. and E.F. Elstner. 1978. Ethane and ethylene formation by mitochondria as indication of aerobic lipid degeneration in response to wounding of plant tissue. Biochim. Biophys. Acta 528:213221.

Lieberman, M. and L.W. Mapson. 1962. Fatty acid control of ethane production by sub-cellular particles from apples and its possible relationship to ethylene biosynthesis. Nature 195:1016-1017.

Mead, J.F. 1976. Free radical mechanisms of lipid damage and consequences for cellular membranes, p. 51-68. In: W.A. Pryor (ed.). Free radicals in biology. vol. I. Academic, New York.

Pauls, K.P. and J.E. Thompson. 1980. In vitro simulation of senescence-related membrane damage by ozone-induced lipid peroxidation. Nature 283:504-509.

Peiser, G.D., M. Concepcion, C. Lizada, and S.F. Yang. 1982. Sulfite-induced lipid peroxidation in chloroplasts as determined by ethane production. Plant Physiol. 70:994-998. 
Riley, C.A., G. Cohen, and M. Lieberman. 1974. Ethane evolution: A new index of lipid peroxidation. Nature 183:208-210.

Roberts, B.R., V.M. Schnipke, and J.H. Barger. 1990. Ethylene evolution and membrane permeability in red maple foliage fumigated with acute sulfur dioxide. HortScience 25:560-561.

Schobert, B. and E.F. Elstner. 1980. Production of hexanal and ethane by Phaeodactylum triconutum and its correlation to fatty acid oxidation and bleaching of photosynthetic pigments. Plant Physiol. 66:215-219.

Shirazi, A.M., L.H. Fuchigami, and T.H.H. Chen. 1990. Heat tol- erance and ethylene production in red-osier dogwood stem tissues at different growth stages. HortScience 25:1143 (Abstr.)

Siedow, J.N. 1991. Plant lipoxygenase: Structure and function. Annu. Rev. Plant Physiol. Plant Mol. Biol. 42:145-188.

Wise, R.R. and A.W. Naylor. 1987. Chilling-enhanced photooxidation. Plant Physiol. 83:272-277.

Yoshida, S. 1979. Freezing injury and phospholipid degradation in vivo in woody plant cells. III. Effects of freezing on activity of membrane-bound phospholipase $\mathrm{D}$ in microsome-enriched membranes. Plant Physiol. 64:252-256. 